\title{
Shared decision making and behavioral impairment: a national study among children with special health care needs
}

\author{
Alexander G Fiks ${ }^{1,2,3,4,5^{*}}$, Stephanie Mayne ${ }^{3,4}$, A Russell Localio ${ }^{6}$, Chris Feudtner ${ }^{3,4,5}$, Evaline A Alessandrini ${ }^{7}$
} and James P Guevara ${ }^{1,3,4,5}$

\begin{abstract}
Background: The Institute of Medicine has prioritized shared decision making (SDM), yet little is known about the impact of SDM over time on behavioral outcomes for children. This study examined the longitudinal association of SDM with behavioral impairment among children with special health care needs (CSHCN).

Method: CSHCN aged 5-17 years in the 2002-2006 Medical Expenditure Panel Survey were followed for 2 years. The validated Columbia Impairment Scale measured impairment. SDM was measured with 7 items addressing the 4 components of SDM. The main exposures were (1) the mean level of SDM across the 2 study years and (2) the change in SDM over the 2 years. Using linear regression, we measured the association of SDM and behavioral impairment.

Results: Among 2,454 subjects representing 10.2 million CSHCN, SDM increased among 37\% of the population, decreased among 36\% and remained unchanged among 27\%. For CSHCN impaired at baseline, the change in SDM was significant with each 1-point increase in SDM over time associated with a 2-point decrease in impairment (95\% Cl: $0.5,3.4)$, whereas the mean level of SDM was not associated with impairment. In contrast, among those below the impairment threshold, the mean level of SDM was significant with each one point increase in the mean level of SDM associated with a 1.1-point decrease in impairment $(0.4,1.7)$, but the change was not associated with impairment.

Conclusion: Although the change in SDM may be more important for children with behavioral impairment and the mean level over time for those below the impairment threshold, results suggest that both the change in SDM and the mean level may impact behavioral health for CSHCN.
\end{abstract}

Keywords: Children with Special Health Care Needs, Communication, Decision-Making

\section{Background}

Shared decision making (SDM) is defined as the active participation of both clinicians and families in treatment decisions, the exchange of information, discussion of preferences, and a joint determination of the treatment plan [1]. Given benefits of SDM in increasing families'

\footnotetext{
*Correspondence: fiks@email.chop.edu

'The Pediatric Research Consortium (PeRC), The Children's Hospital of Philadelphia, 34th Street and Civic Center Boulevard, Philadelphia, PA 19104, USA

${ }^{2}$ Center for Biomedical Informatics (CBMI), The Children's Hospital of Philadelphia, 34th Street and Civic Center Boulevard, Philadelphia, PA 19104 USA

Full list of author information is available at the end of the article
}

knowledge, decreasing uncertainty, and pairing families with treatments they find most acceptable [2], the Institute of Medicine (IOM) recently stressed the importance of research assessing the comparative effectiveness of SDM in pediatrics [3] and the 2010 Patient Protection and Affordable Care Act supported the implementation of SDM in clinical settings [4]. Despite the prioritization of research on SDM, little work has investigated the association of SDM with children's health.

SDM is particularly useful when families must balance the risks and benefits of more than one evidence-based treatment. This process therefore may be especially helpful in the management of behavioral problems since

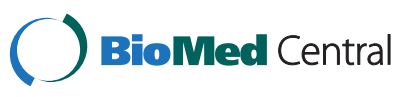


families choose between behavior therapies and medical treatments, often informed by strongly held personal and cultural values. Concerns such as cost, accessibility, stigma, effectiveness, and side effects have been shown to shape these decisions [5]. By addressing families' preferences, SDM explicitly incorporates values into the decision making process. As a result, beliefs that could undermine treatment acceptability, engagement and adherence may be discussed prior to the selection of therapeutic options and potentially lead to a better match between families and treatments.

Children with special health care needs (CSHCN), those who have or are at increased risk of a chronic physical, developmental, behavioral, or emotional condition and who require health and related services beyond that required by children generally [6], are an ideal population for the study of the impact of SDM on behavioral health. Approximately 10 to 12 million United States (US) children have special health care needs [7], up to $30 \%$ of $\mathrm{CSHCN}$ have a behavioral or emotional disorder [8,9], and behavior problems are often more severe among $\mathrm{CSHCN}$ than others [10,11]. Furthermore, even for children without a diagnosed behavioral or mental health condition, the presence of a special health care need often increases the need for mental health services for both affected children and their families [9].

To address these often multi-faceted problems, collaboration between clinicians and families has become a priority for these children. Ensuring "that families partner in decision making at all levels and are satisfied with the services they receive" is one of the Maternal and Child Health Bureau's 6 core outcomes for CSHCN [12]. Still, little attention has focused specifically on the association of SDM with children's behavioral health and how patterns of SDM over time may impact behavioral outcomes. To address this knowledge gap and provide guidance for pediatric clinicians who routinely treat behavioral problems, we conducted a longitudinal study of SDM and behavioral health among a national sample of US CSHCN. We hypothesized that both higher mean levels of SDM over time as well as increasing SDM would be associated with improved behavioral health.

\section{Methods}

\section{Study design and data source}

We conducted a longitudinal analysis of the Medical Expenditure Panel Survey (MEPS), administered annually by the Agency for Healthcare Research and Quality (AHRQ) and previously used to study CSHCN $[13,14]$. Between 12,810 and 14,828 households were sampled annually from the US population, and all children were followed for 2 years [15]. In MEPS, the person from each household who was most knowledgeable about the health of its members provided information on health status, insurance, and utilization. Interviews were supplemented by surveys from medical providers, health insurers, and employers.

\section{Study sample}

The study sample included all children $\geq 5$ and $\leq 17$ years in MEPS panels 7 to 10 (2002- 2006). Younger children were excluded because behavioral impairment is not assessed in MEPS. From this sample, CSHCN were identified using the validated CSHCN Screener [16,17]. Children were excluded if they had no usual source of care (SDM does not apply in this context), their household did not respond to any of the items used to create the SDM measure, or they lacked a value for impairment. Response rates for completion of all survey rounds for the years considered ranged from $58.3 \%$ to $64.7 \%$ [15]. We were able to generalize results to the US population of CSHCN by applying sampling weights that reflect the number of people in the US represented by each respondent.

\section{Outcome measure}

The primary outcome was behavioral impairment in the domains of interpersonal relationships, psychopathology, functioning at school, and use of leisure time as assessed during each of the 2 study years by the validated, parentreported, 13-item Columbia Impairment Scale (CIS), which has previously been used with CSHCN $[18,19]$. Each item is scaled from 0 (no problem) to 4 (a very big problem) and total scores $\geq 15$ indicate impairment. Even small differences in mean score may be clinically meaningful. Differences between 1 and 3 points have been found between groups of children with and without physical abuse [20] and with and without major depression [21].

\section{Independent variables}

SDM was the primary independent variable. We determined families' participation in SDM during each study year by calculating the mean item score of responses to 7 separate MEPS items that address distinct aspects of SDM. These items correspond to the four components of SDM in the most widely accepted definition (Table 1) [1]. After excluding children without a response to any of the 7 SDM items, for each item, $7-15 \%$ of remaining children lacked a response. Multiple imputation with 10 data sets was then used to address missing data on these items in a manner designed to avoid bias and produce correct confidence intervals [22]. In order to examine the impact of both the mean level of SDM over the 2 study years and the change in SDM from year 1 to year 2 on behavioral impairment, we considered 2 aspects of SDM in the analysis. First, we calculated the mean SDM for each subject across the 2 study years ((year 1 mean 
Table 1 Items Included in the Shared Decision Making Score

\begin{tabular}{|c|c|c|c|c|c|}
\hline \multirow{2}{*}{$\begin{array}{l}\text { Shared Decision Making Items from the } \\
\text { Medical Expenditure Panel Survey }\end{array}$} & \multirow{2}{*}{$\begin{array}{l}\text { Corresponding Component(s) of } \\
\text { the Definition of Shared } \\
\text { Decision Making (See Below). }\end{array}$} & \multicolumn{4}{|c|}{ Unweighted distribution of scores $(n, \%)^{1}$} \\
\hline & & 1 (Never) & 2 (Sometimes) & 3 (Usually) & 4 (Always) \\
\hline $\begin{array}{l}\text { If there were a choice between treatments, } \\
\text { how often would your medical provider ask } \\
\text { you to help make the decision? }\end{array}$ & 1,4 & $186(8 \%)$ & $277(11 \%)$ & $591(24 \%)$ & $1400(57 \%)$ \\
\hline $\begin{array}{l}\text { Thinking about the types of medical, traditional } \\
\text { and alternative treatments you are happy with, } \\
\text { how often does your medical provider show } \\
\text { respect for these treatments? }\end{array}$ & 3 & $62(3 \%)$ & $191(8 \%)$ & $584(24 \%)$ & $1617(65 \%)$ \\
\hline $\begin{array}{l}\text { In the last } 12 \text { months, how often did your child's } \\
\text { doctors or other health providers listen carefully } \\
\text { to you? }\end{array}$ & 2,3 & $19(1 \%)$ & $143(6 \%)$ & $541(22 \%)$ & $1751(71 \%)$ \\
\hline $\begin{array}{l}\text { In the last } 12 \text { months, how often did your child's } \\
\text { doctors or other health providers explain things } \\
\text { in a way that you could understand? }\end{array}$ & 2,3 & $19(1 \%)$ & $125(5 \%)$ & $460(19 \%)$ & $1850(75 \%)$ \\
\hline $\begin{array}{l}\text { In the last } 12 \text { months, how often did your child's } \\
\text { doctors or other health providers show respect for } \\
\text { what you had to say? }\end{array}$ & 3,4 & $20(1 \%)$ & $124(5 \%)$ & 477 (19\%) & $1833(75 \%)$ \\
\hline \multirow{2}{*}{$\begin{array}{l}\text { In the last } 12 \text { months, how often did your child's } \\
\text { doctors or other health providers spend enough } \\
\text { time with you? }\end{array}$} & 2 & $53(2 \%)$ & $166(7 \%)$ & $559(23 \%)$ & $1676(68 \%)$ \\
\hline & & $1(\mathrm{No})$ & & & 4 (Yes) \\
\hline $\begin{array}{l}\text { Does a medical person at your usual source of } \\
\text { care present and explain all options to you? }\end{array}$ & 2 & $144(6 \%)$ & & & $2310(94 \%)$ \\
\hline \multicolumn{6}{|l|}{ Components of Shared Decision Making } \\
\hline \multicolumn{6}{|l|}{$\begin{array}{l}\text { (1) Both the doctor and the patient are involved in the } \\
\text { treatment decision-making process; }\end{array}$} \\
\hline \multicolumn{6}{|l|}{ (2) Both share information with each other; } \\
\hline \multicolumn{6}{|c|}{$\begin{array}{l}\text { (3) Both take steps to participate in the decision-making process } \\
\text { by expressing treatment preferences; }\end{array}$} \\
\hline \multicolumn{6}{|c|}{$\begin{array}{l}\text { (4) Both the doctor and the patient ree on the treatment } \\
\text { to implement }\end{array}$} \\
\hline
\end{tabular}

${ }^{1}$ Missing data (7-15\% for each item) was imputed using multiple imputation.

$\mathrm{SDM}+$ year 2 mean SDM)/2). Second, to address the change in SDM, a pattern of increasing, decreasing, or unchanged SDM, we calculated the difference between each subject's SDM score in each year and their mean SDM score over the 2 study years. This approach effectively partitioned the change across the 2 study years and centered all of the change at zero, allowing a longitudinal analysis to be conducted as was appropriate for the data structure.

\section{Covariates and effect modification}

We considered as covariates clinical and demographic variables that might impact the relationship between SDM and behavioral impairment (Table 2). These covariates consisted of demographic characteristics including the child's age (5-12 versus 13-17 years), gender, race (White, Black, other) and Hispanic ethnicity, region of residence (Northeast, Midwest, South, West), parental education (no high school diploma, high school diploma, bachelor's degree, graduate level degree, or other degree), and household income (poor $(<100 \%$ of the applicable poverty line), near poor $(100$ to $<125 \%$ ), low (125 to $<200 \%$ ), middle (200 to $<400 \%$ ), high $(\geq 400 \%))$ as well as any private health insurance (versus other insurance or none). To ensure that findings were not confounded by child health, we adjusted for general health status based on the overall score (low $(<15)$, medium $(15$ to $<20)$, and high $(\geq 20)$ ) from 5 Likert-scaled items derived from the parent-reported Child Health Questionnaire, General Health Subscale [23]. Specifically, we controlled for whether health status improved, remained unchanged, or declined between years 1 and 2 of the study. To control for the impact of specific behavioral treatments, we also adjusted for whether children received any psychotropic medications (includes stimulants, antidepressants, antipsychotics, anticonvulsants, as well as other psychotropic medications such as alpha agonists) or 
Table 2 Comparing Characteristics of Children with Special Health Care Needs (CSHCN), Age 5-17 Years, by Shared Decision Making Pattern ${ }^{1}$

\begin{tabular}{ccc}
\hline Variable Included $\quad$ Excluded & $\begin{array}{c}P \text { value } \\
\text { comparing } \\
\text { Included vs. } \\
\text { excluded }^{2}\end{array}$ \\
\hline
\end{tabular}

Number of children

2454

174

in sample

Number of children

641,000

represented in population

Percent represented

Demographic

Characteristics

Age (Years)

$$
\text { 5-12 }
$$

Female

Race

$$
\begin{aligned}
& \text { White } \\
& \text { Black } \\
& \text { Other }
\end{aligned}
$$

Hispanic

Region

Northeast

Midwest

South

West

Parental Education

$$
\text { No Degree }
$$

High School Complete

Bachelor's Degree

Graduate Level Degree

Other Degree

Poverty

Poor

Near Poor

Low Income

Middle Income

High Income

Insurance Coverage

$$
\text { Any private }
$$

Other

Clinical Characteristics

General Health Status ${ }^{3}$

$$
\text { Increasing }
$$

Unchanged

Decreasing

Diagnosed with ADHD

$\begin{array}{cc}94 \% & 6 \% \\ \% & \%\end{array}$

70.0

30.0

44.0

78.4

16.1

5.5

\begin{tabular}{|c|c|c|c|}
\hline Variable & Included & Excluded & $\begin{array}{c}P \text { value } \\
\text { comparing } \\
\text { Included vs. } \\
\text { excluded }^{2}\end{array}$ \\
\hline Diagnosed with Asthma & 20.1 & 19.3 & 0.8 \\
\hline \multicolumn{4}{|l|}{$\begin{array}{l}\text { Any psychotropic } \\
\text { medication use }\end{array}$} \\
\hline None & 70.7 & 85.6 & 0.01 \\
\hline Year 1 only & 2.9 & 2.8 & \\
\hline Year 2 only & 6.1 & 3.9 & \\
\hline Both years & 20.3 & 6.7 & \\
\hline \multicolumn{4}{|c|}{ Any mental health services use ${ }^{5}$} \\
\hline None & 76.5 & 68.8 & $<0.001$ \\
\hline Year 1 only & 6.1 & 20.1 & \\
\hline Year 2 only & 6.8 & 5.8 & \\
\hline Both years & 10.6 & 5.3 & \\
\hline
\end{tabular}

Table 2 Comparing Characteristics of Children with Special Health Care Needs (CSHCN), Age 5-17 Years, by Shared Decision Making Pattern ${ }^{1}$ (Continued)

${ }^{1}$ Children excluded from the study lacked a usual source of care, had no response to any of the items used to create the SDM measure, or lacked a response to items from the Columbia Impairment Scale used to assess behavioral impairment.

${ }^{2} P$ values calculated by chi-square tests with robust variance estimates accounting for the weighted, clustered, and stratified longitudinal MEPS survey design.

${ }^{3}$ General Health Status determined using the overall score from 5 Likert-scaled items (recoded so that a score of 5 indicates the best health and a score of 1 the worst health) derived from the Child Health Questionnaire, General Health Subscale (child seems less healthy than other children, child has never been seriously ill, child usually catches whatever is going around, expect child will have a healthy life, respondent worries more than is usual about child's health). For each year, the overall score was categorized as (low $(<15)$, medium $(15$ to $<20)$, or high $(\geq 20)$ ).

${ }^{4}$ Psychotropic medications considered included stimulants, antidepressants, antipsychotics, anticonvulsants, as well as other psychotropic medications such as alpha agonists.

${ }^{5}$ Mental health services include visits to a psychiatrist, psychologist, or other mental health professional.

any mental health services (visits to a psychiatrist, psychologist, or other mental health professional) in only the first year, only the second year, both study years or never.

Because our initial analyses demonstrated that the association of SDM with behavioral impairment differed with the baseline level of impairment, we evaluated our primary outcome separately in $\mathrm{CSHCN}$ who were impaired at baseline and in those who were unimpaired. Although the study sample size was too small to test effect modification formally based on diagnosis or treatment receipt, we conducted separate secondary analyses including clinically relevant subpopulations: children diagnosed with asthma, children with attention-deficit/hyperactivity disorder (ADHD), those taking psychotropic medication, and those utilizing mental health services. 


\section{Statistical analysis}

\section{Characteristics of the study sample}

We initially described the weighted proportion of CSHCN in MEPS included versus excluded from the study and compared the characteristics of CSHCN with each pattern of SDM using chi-square tests. We then plotted each subject's SDM score in year 1 versus year 2 to observe differences over time, and calculated Pearson correlation coefficients and p-values. Following guidance from AHRQ, all statistical analyses accounted for the weighted, clustered, and stratified MEPS survey design, an approach that provides conservative estimates that account for repeated measures over time [24]. In all analyses, $\mathrm{P}$ values of $<0.05$ were considered significant.

\section{Assessing the impact of SDM on behavioral impairment}

To assess the association between SDM and CIS score over time, linear models with robust variance estimates that reflect the complex survey design were created with the change in CIS score as the outcome and with the mean level of SDM score across the two years as well as the change in SDM as the 2 independent variables. The use of robust variance estimates as well as change scores limited the impact of the skewed distribution of SDM on confidence bounds and significance levels in our analyses. These models were developed separately for CSHCN who were impaired at baseline and those who were unimpaired. In each analysis, we constructed models with and without covariates. Since the inclusion of covariates did not alter the association of SDM with behavioral health, covariates were dropped from the final models presented in the Results section. Analyses used Stata 10 and 11 (College Station, Texas). The CHOP Institutional Review Board determined this study, which involved only deidentified, publically available data, to be exempt from IRB oversight.

\section{Results}

\section{Study sample}

Based on the survey methodology, the study sample of 2,454 represented a population of 10.2 million US CSHCN. This sample included $94 \%$ of the weighted population of US CSHCN (Table 2). Compared to included children those excluded were significantly more likely to be of Black or other race, to be from the South, to have higher levels of poverty, and no private health insurance. Excluded children were also less likely to be diagnosed with ADHD, less likely to be taking psychotropic medication, and less likely to be utilizing mental health services in both years.

\section{Extent of behavioral impairment and patterns of shared decision making}

At baseline, the mean CIS score among all CSHCN was 10.6 out of 52 and $34.2 \%$ of $\mathrm{CSHCN}$ had impaired behavior (score $\geq 15$ represents impairment). Baseline CIS scores were higher among children diagnosed with ADHD (15.9 versus 9.3, p<0.001) and lower among those with asthma $(8.9$ versus $11.0, \mathrm{p}<0.001)$ compared to other CSHCN. Similarly, CIS scores were higher for those on psychotropic medication versus none (16.7 versus $8.7, \mathrm{p}<.001)$ and receiving mental health services versus none (18.0 versus 9.1, $\mathrm{p}<.0001)$.

At baseline, the mean SDM score among all CSHCN was 3.6 out of 4 . The distribution of responses to the SDM items is shown in Table 1 . Figure 1 plots the mean SDM score for each subject in year 2 by the mean score in year 1 . While the SDM score in year 1 was strongly associated with SDM score in year $2(\mathrm{r}=0.7, \mathrm{p}<0.001)$, $37 \%$ of families reported an increase in SDM, 36\% reported a decrease, and only $27 \%$ remained unchanged. Among those whose SDM score increased, 88\% increased by $<1.0$ (out of 4.0 possible), $11 \%$ increased by 1.0 to $<2.0$, and $1 \%$ increased $\geq 2.0$. Among those whose SDM score decreased, $90 \%$ decreased by $<1.0,9 \%$ decreased by 1.0 to $<2.0$, and $1 \%$ decreased by $\geq 2.0$.

\section{Association of shared decision making with behavioral impairment}

The impact of SDM on behavioral impairment differed among $\mathrm{CSHCN}$ who were impaired versus unimpaired at baseline (Figure 2). Among $\mathrm{CSHCN}$ who were not

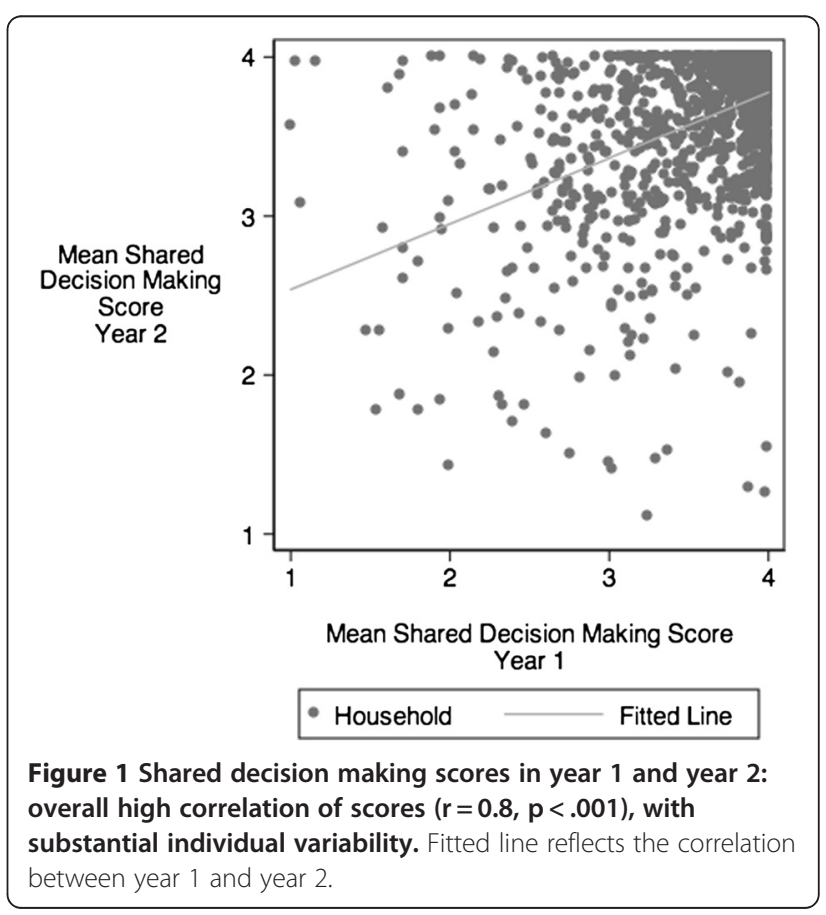


impaired, behavioral impairment scores decreased by 1.1 points $(0.4,1.7)$ with each one point increase in the mean level of SDM (Figure 2A). In this group, the change in SDM over time was not significantly associated with impairment (Figure 2B). In contrast, for CSHCN impaired at baseline, the change in SDM was significant with each 1-point increase in SDM over time associated with a 2-point decrease in impairment (95\% CI: 0.5, 3.4). However, the mean level of SDM was not significantly associated with impairment.

In secondary analyses of subgroups of $\mathrm{CSHCN}$, results were only significant for those receiving mental health services, the subgroup with the highest impairment (Figure 2). Consistent with our main results, the change in SDM, but not the mean level of SDM, was significant with each 1-point increase in SDM over time associated with decreases in impairment of 2.3 points ( $95 \%$ CI: 0.1, 4.6). Trends were similar for other subgroups.

\section{Discussion}

In this study, the first national, longitudinal research project examining the association of SDM with behavioral impairment in children, we hypothesized that both higher sustained levels and increasing patterns of SDM would be associated with decreased impairment among CSHCN. While consistent with our hypothesis, study results showed different patterns of SDM may be most beneficial for children with versus without high levels of impairment at baseline. We found that higher mean levels of SDM were associated with improvements among children below the threshold for behavioral impairment, but only an increase in SDM was associated with significantly improved behavioral health among those with impairment. Although prospective study is warranted to more thoroughly detail how SDM impacts behavioral health, these novel results suggest that increases in SDM may be needed to achieve the best outcomes for children with behavioral impairment, while sustained SDM over time may be more effective to help CSHCN with behavior problems that adversely affect families but fall below the impairment threshold.

A possible explanation for these findings may be the distinct types of decisions that pediatric clinicians and families share when children have varying levels of impairment.

A. Association of Behavioral Impairment with an Increase in

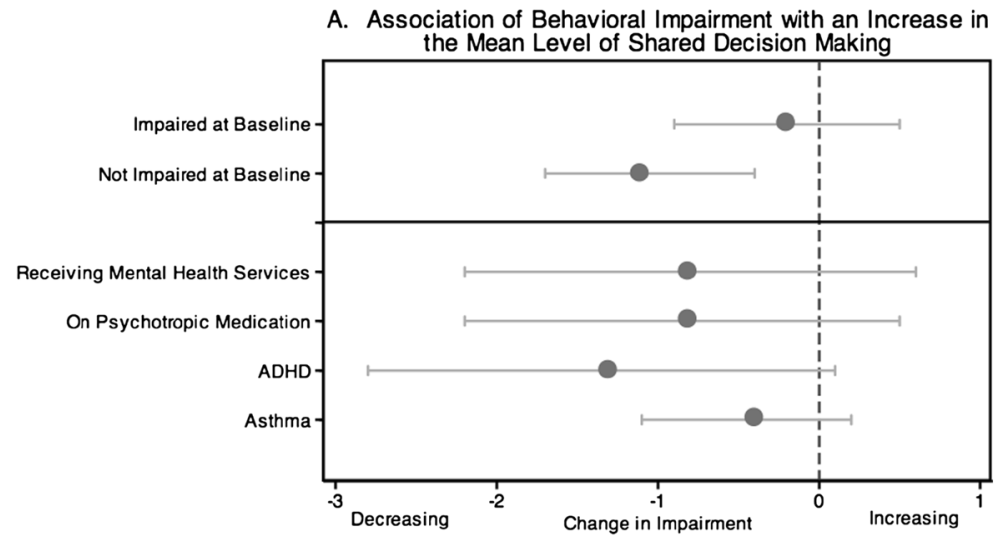

B. Association of Behavioral Impairment with an Increase

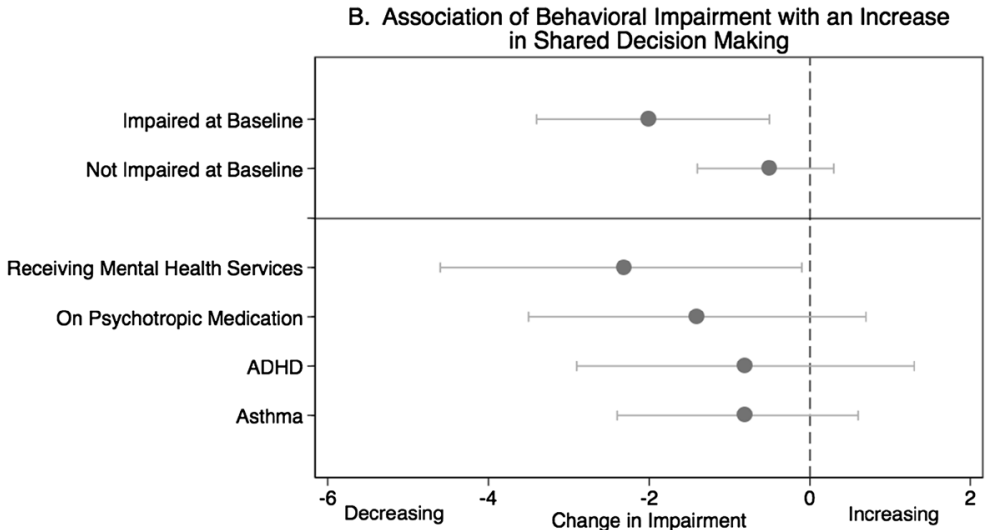

Figure 2 Different groups of CSHCN are affected more by either the mean level of SDM or by an increase in SDM. Plot A shows the decrease in impairment associated with each 1-point increase in the mean level of SDM. Plot B shows the decrease in impairment associated with each 1-point increase in SDM over time, a measure of the change in SDM. 
When children are severely impaired, SDM is likely to focus on starting new medical or behavioral treatments that may result in substantial improvements in behavior. Increasing SDM in this context may maximize the likelihood that these treatments are optimized with input from the family in order to best limit impairment. Sustained SDM, as reflected in the mean, might be less important in this context than increasing SDM specifically when major decisions are reached. In contrast, when behavior problems fall below the impairment threshold, clinicians may instead focus on incremental interventions that make many small improvements over time. In this context, sustained SDM in which families and clinicians jointly address minor difficulties over a period of more than one year may help reduce impairment. Since our findings are novel, further study is needed to better understand and confirm these relationships.

While not directly addressing SDM, the few pediatric interventions designed to improve behavioral health by either fostering communication or the medical home, a broader term including care coordination as well as SDM, have had mixed results. A trial of communication skills training for urban pediatric clinicians led by a psychiatrist and drawing from techniques of familycentered care, family and cognitive behavioral therapy, and family engagement, decreased parent-rated impairment among minority, but not white children with behavior problems [25]. A study of the 2007 National Survey for Children's Health found that children with ADHD cared for in a medical home were less likely to have difficulties participating in activities or making friends [26]. In a rural area, a program to enhance comprehensive, coordinated care for $\mathrm{CSHCN}$ with nurse practitioner home visits, goal setting, and follow-up resulted in improved functioning for the family, but not the child [27].

In the context of mixed findings from these interventions, the benefits of SDM in our results justify prospective study examining the impact of interventions to foster SDM on childhood behavioral health. Extensive research primarily targeting adults has been devoted to developing decision aids, standardized and validated tools specifically created to foster SDM by helping families consider the risks and benefits of specific treatments in the context of their personal values [2]. Decision aid use results in improved decision making, but not consistently improved health outcomes [2]. Unlike decision aids which focus on optimizing individual decisions, the items used in this study assess SDM in the broader context of care which may explain the difference in our findings. Since prior research indicates that improved communication between families at home and their pediatricians is strongly associated with SDM [28] but that SDM occurs inconsistently in clinical encounters with impaired children [29], two types of interventions may be needed: decisions aids to foster SDM within encounters and office-based systems such as expanded telephone hours or patient portals to foster ongoing collaboration and SDM. Office-based staff may also provide outreach to enhance the ongoing shared decision making process.

The longitudinal design of this study allowed us to investigate how patterns of SDM change over time, an area that has received little attention in prior research. We found that 36\% of households reported increasing, $37 \%$ decreasing, and 27\% unchanged SDM. Among possible explanations for these shifts, SDM may increase as families gain experience with different treatment modalities and are better able to participate or may increase or decrease when families switch clinicians and a new partnership develops. Child health status as well as families' outlook and level of stress, factors known to influence pediatric palliative care decision making [30], may also impact families' and clinicians' willingness and ability to participate in SDM.

While this study is the first to use a nationally representative sample to assess the impact of SDM on children's behavioral health over time, it has several limitations. Although we considered 7 items with face validity based on their correspondence with the definition of SDM [1], additional items might have allowed us to further refine our measure and better assess variability in SDM. SDM has been conceptualized as existing between the extremes of paternalistic decision making by the doctor alone and informed decision making by the patient or family alone [1]. However, our study measure limited us to assessing only extent of family involvement in decision making, not who ultimately made decisions. In addition, we relied on household report as opposed to direct observation of SDM. We could not verify how options were presented. Families also might have been more likely to report increased SDM when their children became less impaired, an association that might have biased our results. Although we adjusted for child health status, a similar construct to impairment, and found no impact on results, this might not have fully accounted for the impact of impairment on reported SDM. Furthermore, while our data set provided a national perspective, we conducted an observational study that used a single measure of behavioral health. Trials are needed to definitively assess how SDM impacts behavior using multiple measures of the process and outcomes. Given limits in our sample size that prevented formal tests of effect modification, these studies should also distinguish the impact of SDM in the general population of $\mathrm{CSHCN}$ versus among those with primarily behavioral or physical conditions. 


\section{Conclusions}

We found that SDM was associated with improved behavioral health for US CSHCN. However, different patterns of SDM were associated with improved behavioral health for children with higher versus lower levels of impairment. These results suggest that increasing SDM may be needed to achieve the best outcomes for children with the greatest behavioral impairment, while sustained SDM over time may be more effective to help CSHCN with behavior problems that fall below the impairment threshold. Prospective research is needed to evaluate the impact of strategies to both augment and sustain SDM for this population.

\section{Abbreviations}

SDM: Shared Decision Making; IOM: Institute of Medicine; CSHCN: Children with Special Health Care Needs; US: United States; MEPS: Medical Expenditure Panel Survey; AHRQ: Agency for Healthcare Research and Quality; CIS: Columbia Impairment Scale; ADHD: Attention-Deficit/ Hyperactivity Disorder; CHOP: Children's Hospital of Philadelphia; IRB: Institutional Review Board.

\section{Competing interests}

The authors declare that they have no competing interests.

\section{Author's contributions}

AF conceived of the study, participated in the design and in planning the analysis, and drafted the manuscript. RL, EA, JG, and CF participated in the design of the study and in planning the analysis. SM performed the statistical analysis and assisted in drafting the manuscript. All authors read and approved the final manuscript.

\section{Acknowledgements}

We thank Cyndi Ritz Wallin and Gary Moore of Social \& Scientific Systems, Inc. and Dingwei Dai of The Children's Hospital of Philadelphia Research Institute, Healthcare Analytics Unit for their help with data preparation. Research Support: This research was supported by an Academic Pediatric Association Young Investigator Award and Institutional Development Funds from The Children's Hospital of Philadelphia. In addition, the project described was supported by Award Number K23HD059919 from the Eunice Kennedy Shriver National Institute of Child Health \& Human Development. The content is solely the responsibility of the authors and does not necessarily represent the official views of the Eunice Kennedy Shriver National Institute of Child Health \& Human Development or the National Institutes of Health.

\section{Author details \\ ${ }^{1}$ The Pediatric Research Consortium (PeRC), The Children's Hospital of Philadelphia, 34th Street and Civic Center Boulevard, Philadelphia, PA 19104, USA. ${ }^{2}$ Center for Biomedical Informatics (CBMI), The Children's Hospital of Philadelphia, 34th Street and Civic Center Boulevard, Philadelphia, PA 19104, USA. ${ }^{3}$ Center for Pediatric Clinical Effectiveness, The Children's Hospital of Philadelphia, 34th Street and Civic Center Boulevard, Philadelphia, PA 19104, USA. ${ }^{4}$ PolicyLab, The Children's Hospital of Philadelphia, 34th Street and Civic Center Boulevard, Philadelphia, PA 19104, Pennsylvania. ${ }^{5}$ Department of Pediatrics, Perelman School of Medicine at the University of Pennsylvania, 3620 Hamilton Walk, Philadelphia, PA 19104, USA. ${ }^{6}$ Department of Biostatistics and Epidemiology, Perelman School of Medicine at the University of Pennsylvania, 3620 Hamilton Walk, Philadelphia, PA 19104, USA. ${ }^{7}$ The James M. Anderson Center for Health Systems Excellence, Cincinnati Children's Hospital Medical Center, 3333 Burnet Avenue, Cincinnati, $\mathrm{OH}$ 45229, USA.}

Received: 13 April 2012 Accepted: 17 September 2012 Published: 21 September 2012
References

1. Charles C, Gafni A, Whelan T: Shared decision-making in the medical encounter: what does it mean? (or it takes at least two to tango). Soc Sci Med 1997, 44(5):681-692.

2. O'Connor AM, Bennett CL, Stacey D, Barry M, Col NF, Eden KB, et al: Decision aids for people facing health treatment or screening decisions. Cochrane Database Syst Rev 2009, (3):CD001431.

3. Institute of Medicine (U.S.), Committee on Comparative Effectiveness Research Prioritization: Initial National Priorities for Comparative Effectiveness Research. Washington, D.C: National Academy Press; 2009.

4. The Patient Protection and Affordable Care Act: Public Law No:111-148. United States of America: 124 Stat 1025 111th Congress; 2010.

5. Olaniyan O, DosReis S, Garriett V, Mychailyszyn MP, Anixt J, Rowe PC: Community perspectives of childhood behavioral problems and ADHD among African American parents. Ambul Pediatr 2007, 7(3):226-231.

6. McPherson M, Arango P, Fox H, Lauver C, McManus M, Newacheck PW, et al: A new definition of children with special health care needs. Pediatrics 1998, 102(1 Pt 1):137-140

7. US Department of Health and Human Services Health Resources and Services Administration, Maternal and Child Bureau: The National Survey of Children with Special Health Care Need Chartbook 2005-2006. Rockville, MD: US Department of Health and Human Services; 2007.

8. Canty-Mitchell J, Austin JK, Jaffee K, Qi RA, Swigonski N: Behavioral and mental health problems in low-income children with special health care needs. Arch Psychiatr Nurs 2004, 18(3):79-87.

9. Ganz ML, Tendulkar SA: Mental health care services for children with special health care needs and their family members: prevalence and correlates of unmet needs. Pediatrics 2006, 117(6):2138-2148.

10. Weiland SK, Pless IB, Roghmann KJ: Chronic illness and mental health problems in pediatric practice: results from a survey of primary care providers. Pediatrics 1992, 89(3):445-449.

11. Gortmaker SL, Walker DK, Weitzman M, Sobol AM: Chronic conditions, socioeconomic risks, and behavioral problems in children and adolescents. Pediatrics 1990, 85(3):267-276.

12. McPherson M, Weissman G, Strickland BB, van Dyck PC, Blumberg SJ, Newacheck PW: Implementing community-based systems of services for children and youths with special health care needs: how well are we doing? Pediatrics 2004, 113(5 Suppl):1538-1544.

13. Hudson JL, Miller GEP, Kirby JB: Explaining Racial and Ethnic Differences in Children's Use of Stimulant Medications. Medical Care 2007, 45(11):1068-1075.

14. Stevens J, Harman JS, Kelleher KJ: Race/ethnicity and insurance status as factors associated with ADHD treatment patterns. J Child Adolesc Psychopharmacol 2005, 15(1):88-96.

15. Agency for Healthcare Research and Quality: Medical Expenditures Panel Survey. www.meps.ahrq.gov/mepsweb/survey_comp/household.jsp.

16. Bethell CD, Read D, Stein RE, Blumberg SJ, Wells N, Newacheck PW: Identifying children with special health care needs: development and evaluation of a short screening instrument. Ambul Pediatr 2002, 2(1):38-48.

17. Carle AC, Blumberg SJ, Poblenz C: Internal psychometric properties of the children with special health care needs screener. Acad Pediatr 2011, 11(2):128-135

18. Harris ES, Canning RD, Kelleher KJ: A Comparison of Measures of Adjustment, Symptoms, and Impairment among Children with Chronic Medical Conditions. J Am Acad Child Adolesc Psychiatry 1996, 35(8):1025-1032.

19. Bird HR, Andrews H, Schwab-Stone M, Goodman S, Culcan M, Richters J, et al: Global Measures of Impairment for Epidemiologic and Clinical Use with Children and Adolescents. Int J Methods Psychiatr Res 1996, 6:295-307.

20. Flisher AJ, Kramer RA, Hoven CW, Greenwald S, Alegria M, Bird HR, et al: Psychosocial characteristics of physically abused children and adolescents. J Am Acad Child Adolesc Psychiatry 1997, 36(1):123-131.

21. Goodman SH, Schwab-Stone M, Lahey BB, Shaffer D, Jensen PS: Major depression and dysthymia in children and adolescents: discriminant validity and differential consequences in a community sample. J Am Acad Child Adolesc Psychiatry 2000, 39(6):761-770.

22. Little R, Rubin D: Statistical Analysis with Missing Data:: John Wiley \& Sons, Inc: 1986

23. Landgraf J, Abaetz L: The CHQ User's Manual. First Editionth edition. Boston, MA: The Health Institute, New England Medical Center; 1996. 
24. Machlin S, Yu W, Zodet M: Computing Standard Errors for MEPS Estimates: Agency for Healthcare Research and Quality. http://www.meps.ahrq.gov/ mepsweb/survey_comp/standard_errors.jsp.

25. Wissow LS, Gadomski A, Roter D, Larson S, Brown J, Zachary C, et al: Improving Child and Parent Mental Health in Primary Care: A ClusterRandomized Trial of Communication Skills Training. Pediatrics 2008, 121(2):266-275.

26. Toomey SL, Chan E, Ratner JA, Schuster MA: The patient-centered medical home, practice patterns, and functional outcomes for children with attention deficit/hyperactivity disorder. Acad Pediatr 2011, 11(6):500-507.

27. Farmer JE, Clark MJ, Sherman A, Marien WE, Selva TJ: Comprehensive primary care for children with special health care needs in rural areas. Pediatrics 2005, 116(3):649-656.

28. Fiks AG, Localio AR, Alessandrini EA, Asch DA, Guevara JP: Shared DecisionMaking in Pediatrics: A National Perspective. Pediatrics 2010, 126(2):306-314.

29. Brinkman WB, Hartl J, Rawe LM, Sucharew H, Britto MT, Epstein JN: Physicians' shared decision-making behaviors in attention-deficit/ hyperactivity disorder care. Arch Pediatr Adolesc Med 2011, 165(11):1013-1019.

30. Feudtner C: Collaborative communication in pediatric palliative care: a foundation for problem-solving and decision-making. Pediatr Clin North Am 2007, 54(5):583-607. ix.

\section{Submit your next manuscript to BioMed Central and take full advantage of:}

- Convenient online submission

- Thorough peer review

- No space constraints or color figure charges

- Immediate publication on acceptance

- Inclusion in PubMed, CAS, Scopus and Google Scholar

- Research which is freely available for redistribution 